\title{
Pitting corrosion on anodized titanium: effect of halides
}

\begin{tabular}{|r|l|}
\hline Journal: & Materials and Corrosion \\
\hline Manuscript ID & Draft \\
\hline Datey - Manuscript type: & Article \\
\hline Complete List of Authors: & $\begin{array}{l}\text { Prando, Davide; Politecnico di MIlano, Chemistry, Material, Chemical } \\
\text { engineering } \\
\text { Nicolis, Davide; Politecnico di MIlano, Chemistry, Material, Chemical } \\
\text { engineering } \\
\text { Pedeferri, MariaPia; Politecnico di MIlano, Chemistry, Material, Chemical } \\
\text { engineering } \\
\text { Ormellese, Marco; Politecnico di MIlano, Chemistry, Material, Chemical } \\
\text { engineering }\end{array}$ \\
\hline Keywords: & Titanium, Anodizing, Halides, Oxide, Pitting \\
\hline & \\
\hline
\end{tabular}

SCHOLARONE

Manuscripts 


\title{
Pitting corrosion on anodized titanium: effect of halides
}

\author{
D. Prando, D. Nicolis, M. Pedeferri, M. Ormellese \\ Politecnico di Milano, Department of Chemistry, Materials and Chemical Engineering "Giulio \\ Natta”, Via Mancinelli 7, 20131 Milan, Italy \\ Corresponding author: Marco Ormellese, email: marco.ormellese@polimi.it
}

\begin{abstract}
Titanium corrosion resistance is high in the majority of environments. However, titanium is susceptible to different forms of corrosion, if exposed to high concentrated halides containing solutions. To face this corrosion problem, expensive titanium alloys are used. An alternative method, consisting of electrochemical anodizing treatment, which promote the formation of a compact titanium oxide on the surface, could be applied to increase titanium corrosion resistance. In this work, titanium samples anodized at $20 \mathrm{~V}$ in $\mathrm{H}_{2} \mathrm{SO}_{4} 0.5 \mathrm{M}$ have been tested in sodium fluorides, chlorides, bromides and iodides at $0.5 \mathrm{M}$ and 2.0 $\mathrm{M}$ in order to define halides aggressiveness.
\end{abstract}

Keywords: Titanium; anodizing, halides, oxide, pitting. 


\section{Introduction}

Titanium is one of the most used metals when corrosion resistance is needed, thanks to the thin, amorphous titanium dioxide layer formed in aerated environment [1-2]. Titanium is used in many application fields, often characterized by very severe chemical of physical conditions, such as strongly acidic environments, high temperatures, variable pressure, offshore drilling, marine or aerospace environments [2-5].

Due to its strong tendency to passivate and self-protect in presence of oxygen and water, titanium is used to manufacture components subject to wet environments. All natural waters contain dissolved salts. The anions of some salts, particularly $\mathrm{F}^{-}, \mathrm{Cl}^{-}, \mathrm{Br}^{-}$and $\mathrm{I}^{-}$, can cause local breakdown of the protective film and initiate pitting or other forms of localized corrosion, which rapidly propagates [6-10].

Pitting corrosion of titanium occurs rarely at temperatures below $100^{\circ} \mathrm{C}$, except in very aggressive media, characterized by high temperature, high halides content and reducing conditions, with low oxygen content, low $\mathrm{pH}$ and presence of acid compounds. Pitting phenomena could initiate when the electrode potential of titanium exceeds a certain critical value, known as the pitting potential [11]. Pitting potential of titanium alloys in chloride solutions, i.e. seawater concentration, at room temperature is several volts more noble than the spontaneous corrosion potential. Accordingly, pitting may occur only if the metal is polarized up to the pitting potential by an anodic current [11]. However, such behaviour cannot be extended to other halides: in bromides containing solutions, for example, pitting can occur at voltages as low as $1.1 \mathrm{~V}$ [8]; in fluoride electrolytes, titanium oxide is completely dissolved due to the formation of soluble Ti-F salts.

The most detailed investigations of pitting corrosion of bare titanium in halide solutions are described by Dugdale and Cotton [7] and by Beck [13-14]. The experimental data show that several complex events occur during corrosion. The reaction is not under simple kinetic, mass-transport, or ohmic control. However, regardless of the halide species present as anion in the dissolved salt, 
titanium is believed to undergo a half-reaction of ionization from $T i$ to $T i^{4+}$, without generation of $T i^{3+}$ ions. Such reaction is promoted by the permeation of halide anions through the titanium oxide layer, when the applied potential is high enough to break the dielectric resistance of the oxide layer:

$$
T i+4 X^{-} \rightarrow T i X_{4}+4 e^{-}
$$

In the model theorized by Beck (Figure 1) the formation of the tetrahalide causes a removal of the thin oxide layer, promoting instead the formation of a salt film, whose actual formation has been experimentally observed [8]. The simplest composition, $\mathrm{TiX}_{4}$ is chosen, although it could also be $\mathrm{TiOX}_{2}$ or some other oxy-halide salt of $\mathrm{Ti}^{4+} . \mathrm{TiX}_{4}$ then reacts with water in the diffusion layer, to give titanium oxide, which precipitates, and $\mathrm{TiO}^{2+}$, which remains in the solution, generating $\mathrm{H}^{+}$, decreasing the $\mathrm{pH}$, and regenerating $X^{-}$that reacts again with titanium, working as a highconcentration catalyst. The $X^{-}$anion is transported by high-field conduction through the salt to metal surface. The overall pit reaction is:

$$
\mathrm{Ti}+2 \mathrm{H}_{2} \mathrm{O} \rightarrow \mathrm{TiO}_{2}+4 \mathrm{H}^{+}+4 e^{-}
$$

and

$$
\mathrm{Ti}+\mathrm{H}_{2} \mathrm{O} \rightarrow \mathrm{TiO}^{++}+2 \mathrm{H}^{+}+4 e^{-}
$$

At steady state, water is the only species transported into the pit from the environment, while $\mathrm{TiO}_{2}$, $T i 2$ and $H^{+}$are transported out. 


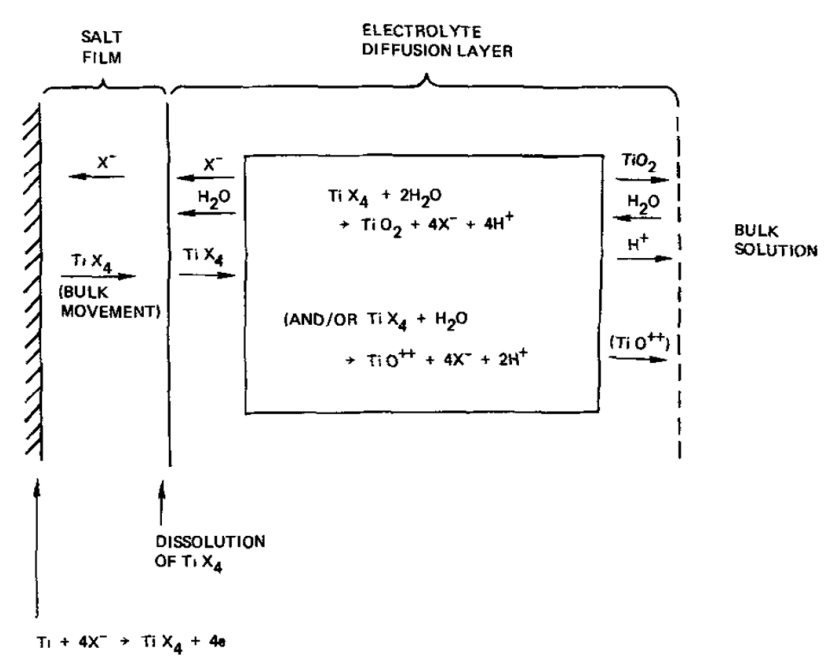

Figure 1 - Model for reactions in pit

Reverse potentiodynamic test starting from pitting potential revealed that titanium repassivation is difficult to achieve, due to very large hysteresis loop. A quantitative measurement of repassivation potential is hard due to a very high dependency on experimental parameters [15].

To increase corrosion resistance of commercial purity titanium, surface treatments are available, such as chemical and thermal treatments or electrochemical anodizing [16]. The latter is the most promising one. It consists of anodically polarize titanium in a specific acidic electrolyte, by imposing an anodic voltage between titanium and a counter electrode. The treatment is performed at fixed anodic current density, allowing the cell voltage to increase at a proper value. Such treatment promotes the formation of a thicker, more protective $\mathrm{TiO}_{2}$ layer on the surface, whose effectiveness in protecting the metal underneath has already been proven in several applications $[8,17]$. The anodized films are compact, have better hardness, improve both corrosion and wear resistance fatigue, increase lubricity and reduce the sensitivity to galvanic corrosion of titanium alloys [18-22], especially when the proper solution is used to prevent hydrogen embrittlement [23]. Moreover, certain specific anodizing treatments allow $\mathrm{TiO}_{2}$ to form as a penetrating layer rather than growth at the surface, which results in no dimensional change [18]. 
In the present work, the corrosion resistance of anodized titanium has been investigated in halides containing solution $\left(\mathrm{F}^{-}, \mathrm{Cl}^{-}, \mathrm{Br}^{-}\right.$and $\left.\mathrm{I}^{-}\right)$by potentiodynamic polarization tests, imposing an increasing anodic potential. Results clearly show that fluoride ions are the more severe, promoting a general dissolution of the oxide film, while chlorides are the less aggressive. Bromide and iodide containing solutions promote localized corrosion, with a clear passive film breakdown.

\section{Experimental procedure}

\subsection{Sample preparation}

Square samples, $19 \mathrm{~mm}$ by side, $1.6 \mathrm{~mm}$ thick, were cut from a commercial purity titanium plate UNS R50400, titanium Gr. 2 according to ASTM B861 [24]: oxygen content less than $0.25 \%$, iron less than $0.3 \%$ and $\mathrm{C}$ less than $0.1 \%$.

To remove working grease and dust, samples were ultrasonically degreased in ethanol for 4 min, then rinsed in distilled water. Then, to remove possible contamination and adsorbed species from metal surface and to ensure the same surface finishing, samples were etched and mechanically polished. Etching was performed in $5 \%$ hydrofluoric acid $+35 \%$ nitric acid solution for 2 min, solution volume was at least $400 \mathrm{ml}$ for each sample and samples were kept vertical while etching process was taking place. Mechanical polishing was performed with 100 and 320 grit SiC papers. Both the procedures were followed by ethanol ultrasonic bath and distilled water rinsing.

After surface polishing, samples were electrochemically anodized in galvanostatic condition in $\mathrm{H}_{2} \mathrm{SO}_{4}$ 0.5 M, applying $20 \mathrm{~mA} / \mathrm{cm}^{2}$ with an AimTTi PLH120 DC power supply, able to operate up to $120 \mathrm{~V}$ and $0.75 \mathrm{~A}$. Current was maintained a cell voltage of $20 \mathrm{~V}$ was reached. Titanium oxide thickness is $40 \mathrm{~nm}$.

\subsection{Testing procedure}

After surface treatments, samples corrosion resistance was analyzed with potentiodynamic tests using a MetroOhm Autolab potentiostat M204. Tests were performed according to EN ISO 17475 $[25]$. 
To ensure independency from the cation, all solutions were prepared using sodium salts. Tests were conducted in $1 \mathrm{~L}$ volume cell, filled with $\mathrm{NaF}, \mathrm{NaCl}, \mathrm{NaBr}$ or $\mathrm{NaI} 0.5 \mathrm{M}$ and $2.0 \mathrm{M}$.

Open circuit potential (OCP) was monitored for $1 \mathrm{~h}$ after sample immersion into the testing solution with a potassium chloride saturated silver/silver chloride reference electrode (SSC). Then potential was scanned from $-0.1 \mathrm{~V}$ to $9 \mathrm{~V}$ with respect the OCP at a potential scan rate of $20 \mathrm{mV} / \mathrm{min}$ until breakdown potential was reached. Anodic current and potential difference between metal and reference electrode were registered with $\mathrm{Nova}^{\circledR} 2.1 .1$ software. Temperature was $20^{\circ} \mathrm{C} \pm 2{ }^{\circ} \mathrm{C}$. pH was 7. For each solution tests were repeated three times.

\section{Results}

Figure 2 shows potentiodynamic curves obtained in halide containing solution at $0.5 \mathrm{M}$ concentration. For each solution, two representative curves are reported. Anodized titanium shows similar behavior in all the tested halides up to a potential of about $3.5 \mathrm{~V} \mathrm{SSC}$. The anodic current density is in the range $0.01-0.1 \mathrm{~A} / \mathrm{m}^{2}$. Bromides promote localized corrosion of the passive layer: breakdown potential is in the range 4.2-4.7 V SSC. In the presence of chloride, anodized titanium remains passive. No increase of anodic current density was observed up to 7 V SSC. In fluoride and iodide containing solution anodic current density increases at increasing potential, indicating an active behaviour of titanium.

The same tests were conducted at higher halides concentration, $2.0 \mathrm{M}$, in order to better verify the different effect on titanium corrosion resistance. Moreover, for comparison titanium was also tested in a neutral non-aggressive electrolyte, sodium sulphate 2.0 M. Results are reported in Figure 3.

As expected, sulphate solution does not corrode the anodized titanium. The anodic curve is typical of a passive metal, with an almost constant anodic current density at increasing anodic potential. The same behaviour, even with a lowest anodic current density, was observed on titanium immersed in chloride containing solution. Pitting corrosion does not occur even at 7 V SSC. 
Only bromide ions promote localized corrosion: a clear breakdown potential was detected at $2.4 \mathrm{~V}$ and 2.7 V SSC, at which the anodic current density exponentially increases to very high values.

In fluoride containing solution, no passive interval can be observed. the anodic current density increases as the anodic potential increases. The protective film is dissolved and titanium is uniformly corroded.

In iodide solution, no clear breakdown potential is detectable, even if the anodic current density increases as the potential increases.

At the end of each test, sample surface was visually inspected to confirm the corrosion morphology.

In both sulphates and chlorides solution (Figure 4) an oxide colour change was observed, without any significant localized corrosion attack, thus confirm results obtained by potentidynamic tests. Being titanium oxide colours produced by light interference, they are strongly dependent on oxide thickness: small variation in thickness produce a high variation in sample colour. As the tested samples are still coloured (inner part of the circle in Figure 4) and no localized corrosion is present, the titanium oxide is still present and corrosion did not reach the metal. Figure 5 shows the appearance of samples tested in iodides and fluorides. They caused titanium oxide dissolution and underlying titanium exposure to the surface. 


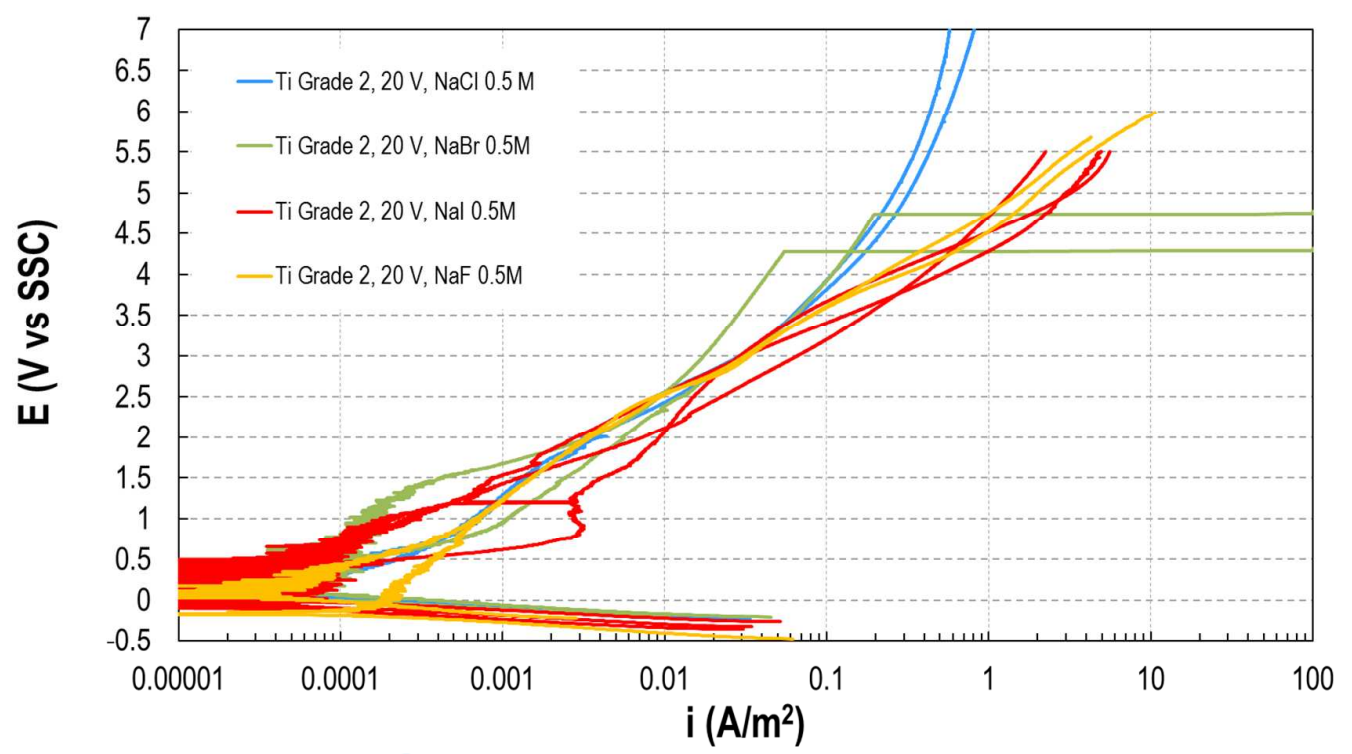

Figure 2 Potentiodynamic curves of samples anodized at $20 \mathrm{~V}$ and tested in $\mathrm{NaCl}, \mathrm{NaBr}, \mathrm{NaI}$ and

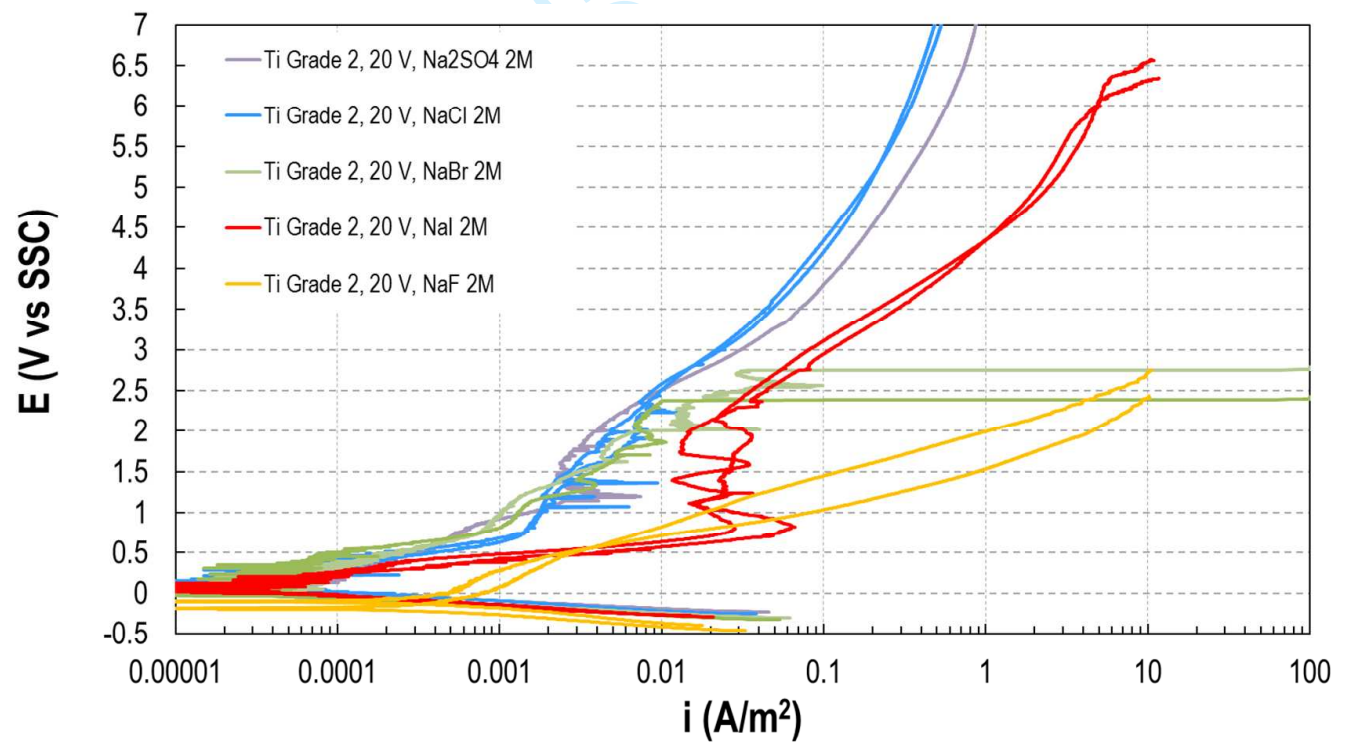

Figure 3 Potentiodynamic curves of samples anodized at $20 \mathrm{~V}$ and tested in $\mathrm{NaCl}, \mathrm{NaBr}, \mathrm{NaI}$ and NaF $2.0 \mathrm{M}$. 

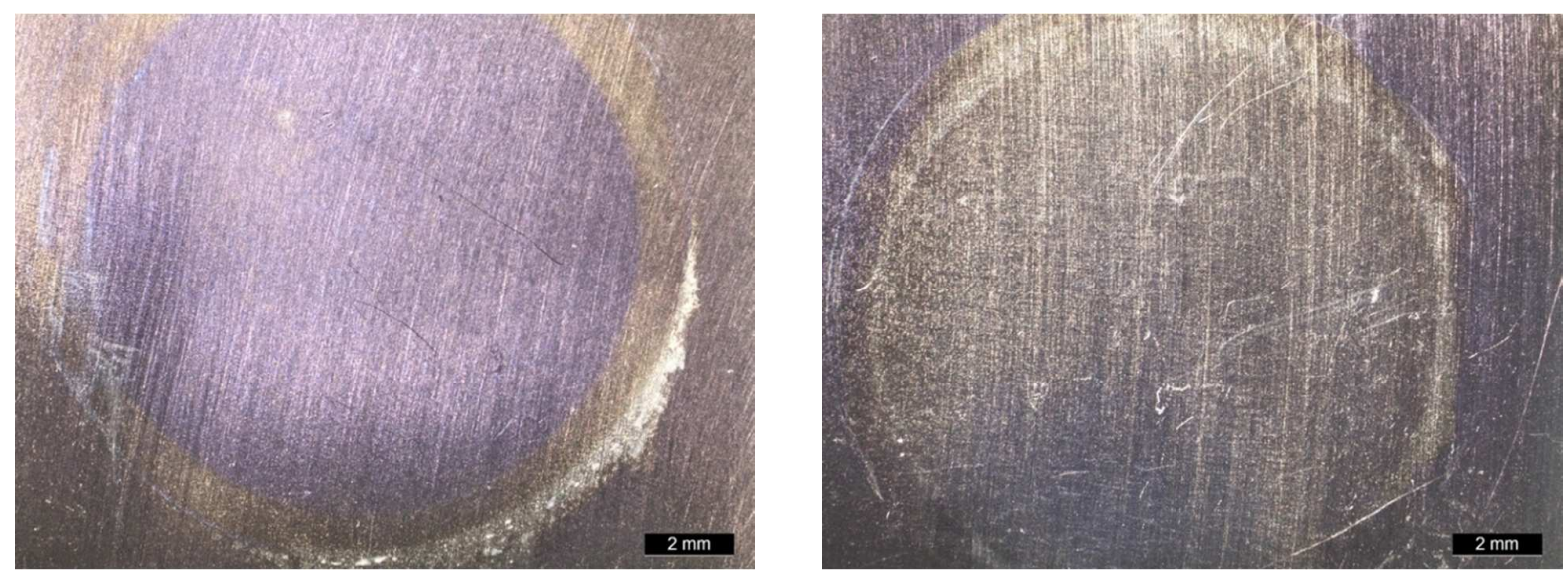

Figure 4 - Sample appearance after potentiodynamic tests in $\mathrm{Na}_{2} \mathrm{SO}_{4} 2 \mathrm{M}$ (left) and $\mathrm{NaCl} 2 \mathrm{M}$ (right).
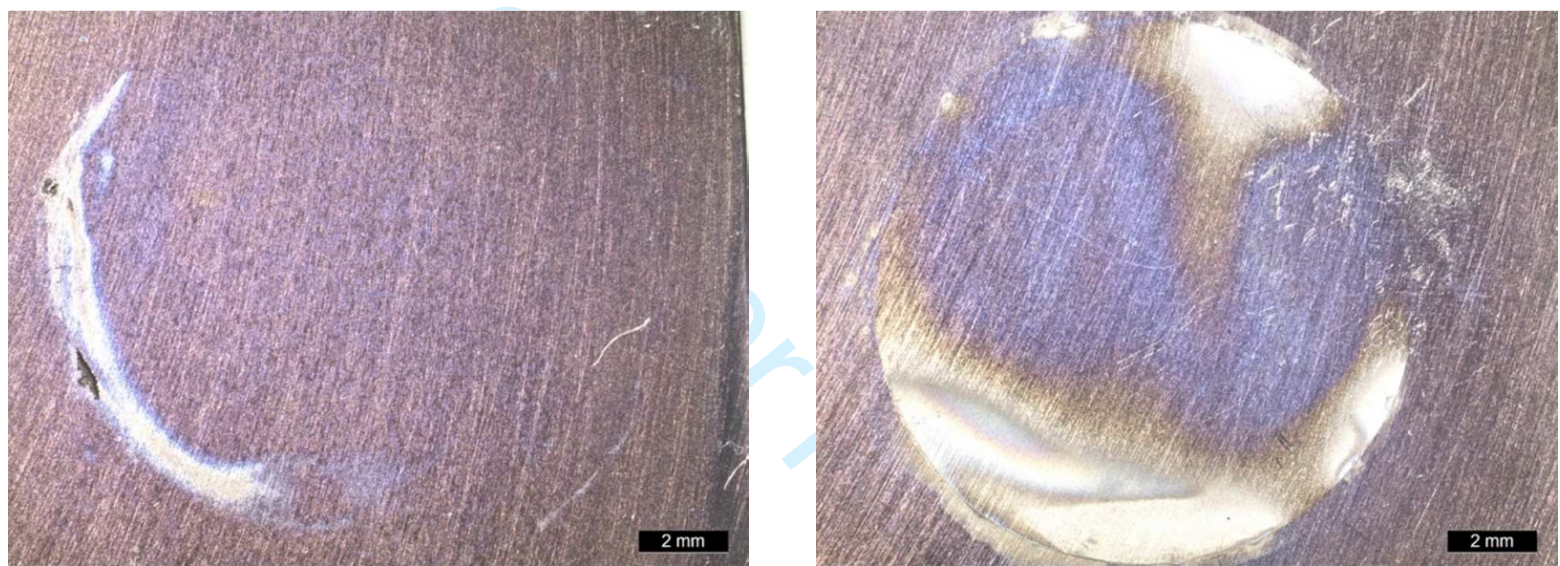

Figure 5 - Sample appearance after potentiodynamic tests in NaI $2 M$ (left) and NaF $2 M$ (right).

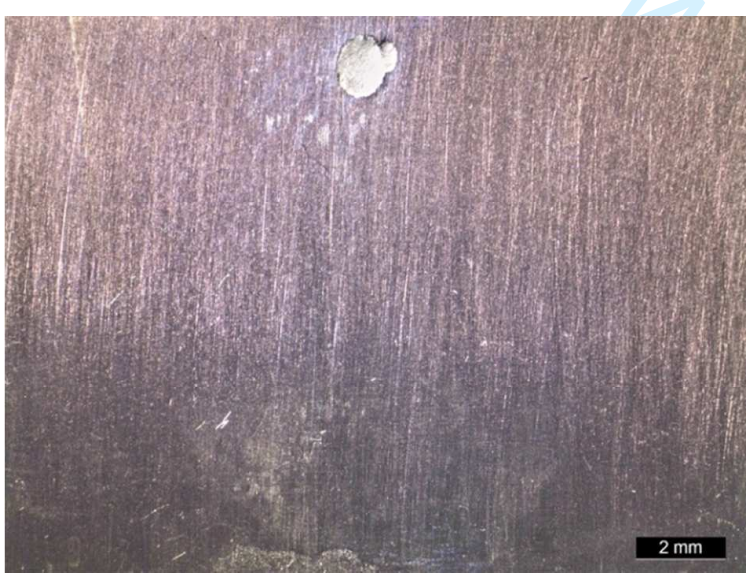

Figure 6 - Sample appearance after potentiodynamic tests in $\mathrm{NaBr} 2 \mathrm{M}$. 
Moreover, in the presence of iodides a localized corrosion starting from the boundary of tested region is visible. Fluorides cause a much severe attack, with total oxide disruption. As expected from electrochemical results, bromides show only localized attack (Figure 6), in the form of a big and deep crater on sample surface, without any oxide removal outside the localized corrosion region.

\section{Discussion}

Potentiodynamic tests are analysed in order to define the effect of halides on the stability of the titanium oxide layer formed on commercially pure titanium by means of electrochemical anodizing treatment. Results will be compared with the available literature.

To compare the corrosion behaviour, electrochemical data were elaborated by taking the anodic current density from each potentiodynamic test at $1 \mathrm{~V}, 2 \mathrm{~V}, 3 \mathrm{~V}, 4 \mathrm{~V}$ and $5 \mathrm{~V}$ SSC. The analysis has been carried out on both tests performed in halide concentration $0.5 \mathrm{M}$ (Figure 7) and 2.0 M (Figure 8).

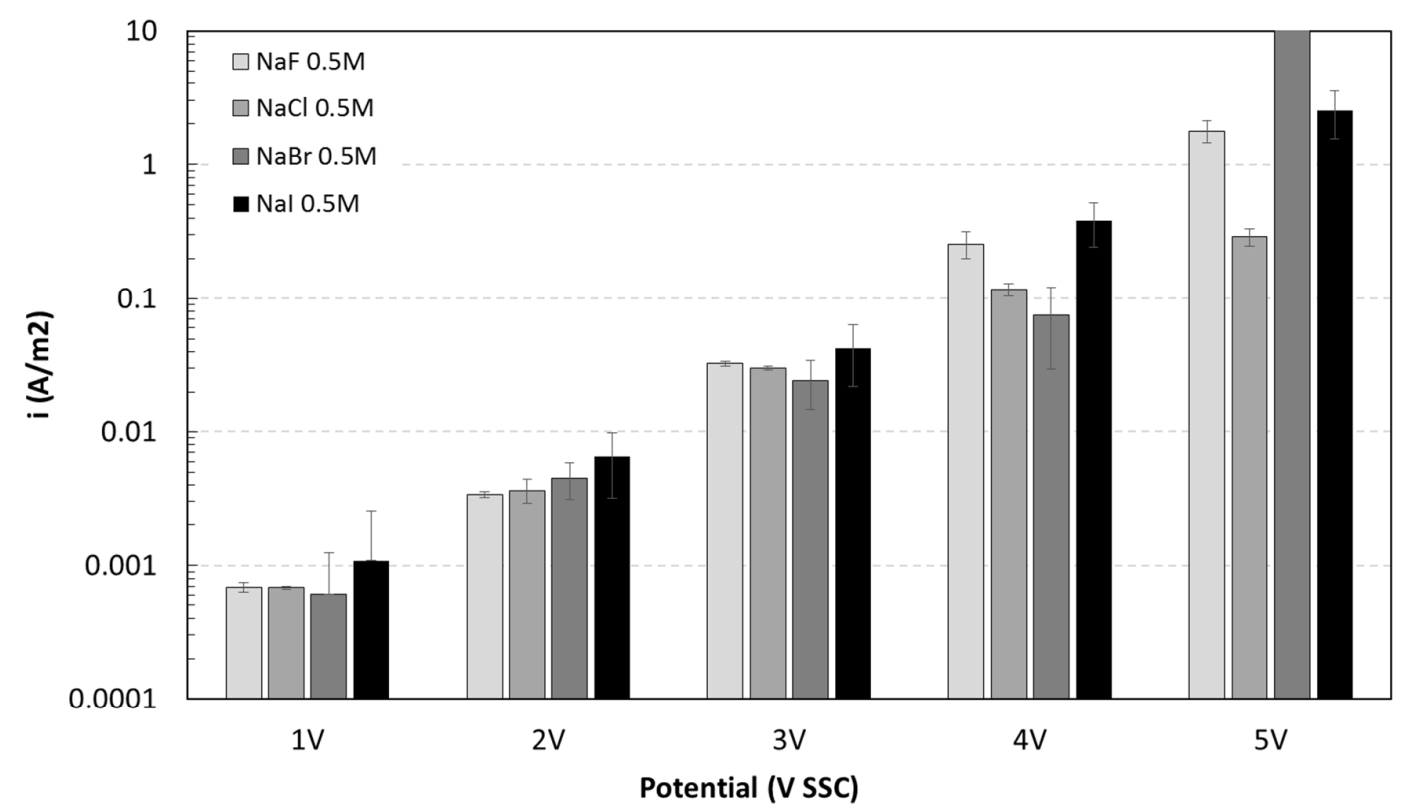

Figure 7 - Anodic current density in different halide salts at $0.5 \mathrm{M}$ at $1 \mathrm{~V}, 2 \mathrm{~V}, 3 \mathrm{~V}, 4 \mathrm{~V}$ and $5 \mathrm{~V}$ SSC. 


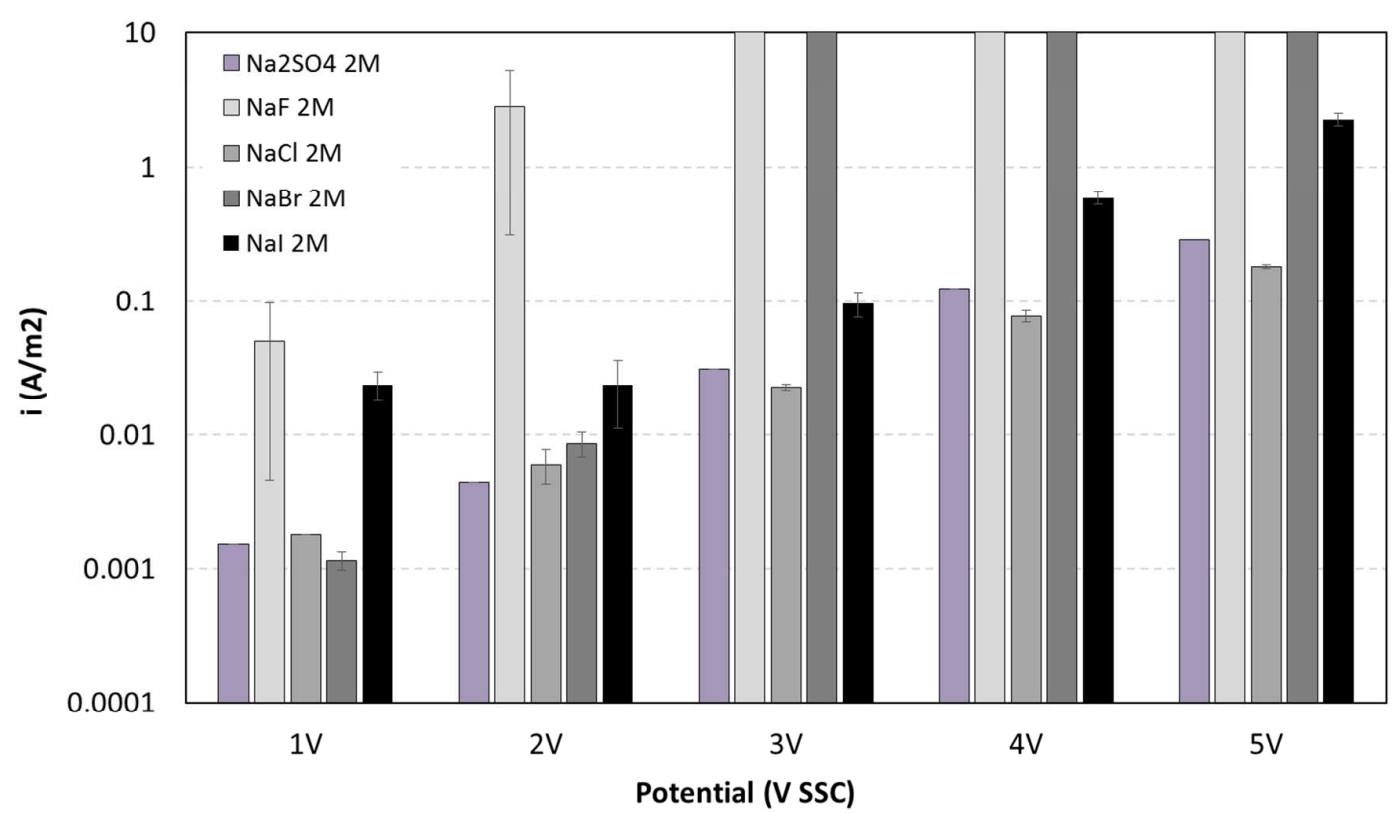

Figure 8-Anodic current density in different halide salts at $2.0 \mathrm{M}$ at $1 \mathrm{~V}, 2 \mathrm{~V}, 3 \mathrm{~V}, 4 \mathrm{~V}$ and $5 \mathrm{~V}$ SSC.

At salt concentration of $0.5 \mathrm{M}$, as previously described, anodic current density of anodized titanium is similar in all the electrolytes, with iodides showing a slightly higher aggressiveness with respect to the others. At $4 \mathrm{~V} \mathrm{SSC}$ and $5 \mathrm{~V} \mathrm{SSC}$ bromides caused localized oxide breakdown, with a sharp increase of current density.

At 2.0 M concentration, a clear difference is noticeable. Chlorides are not enough aggressive to both initiate localized corrosion and to cause generalized corrosion of titanium oxide; the measured behaviour is similar to reference neutral electrolyte in the whole potential range scanned, up to $7 \mathrm{~V}$ SSC. In this solution, titanium has the lowest anodic current densities, i.e. the highest corrosion resistance. As reported in literature $[12,27]$, in the presence of chlorides ions, breakdown potential several volts more positive than the free corrosion potential is necessary to initiate corrosion on titanium. Localized corrosion is caused by the migration of the ions across the passive film. Accumulation of oxychloride at the metal-film interface is responsible of the oxide film rupture, as nucleation event. Up to $7 \mathrm{~V} \mathrm{SSC}$ neither penetrating pits nor nucleation spots has been observed. 
Fluoride ions are the more aggressive halides; they caused the film to be in active electrochemical condition, forming very soluble $\mathrm{TiF}_{4}$ salts, such as $\mathrm{TiF}_{6}{ }^{2-}$ and $\mathrm{TiF}_{6}{ }^{3-}$ [28], leading to uniform dissolution of the film: a logarithmic increase in anodic current density with increasing potential is noticeable. When passivity is lost an abrupt increase in corrosion rate and a decrease in open circuit potential was observed. Nakagawa et al. [29] investigated how the $\mathrm{pH}$ threshold for titanium corrosion varies with $\mathrm{F}^{-}$concentration and they identify a linear correlation between $\mathrm{pH}$ threshold and logarithm of fluoride concentration. In the range $0.5-2.0 \mathrm{M}$ fluoride ions content, they stated a neutral solution, like in our tested condition, is more than enough to corrode and dissolve the titanium oxide. Further investigations from Lindholm-Sethson and Ardlin [30] highlighted the existence of three different conditions for titanium in fluoride solution: passive, non-passive and active. The three conditions can be distinguished by the value of free corrosion potential obtained after long exposure to electrolytes with different fluoride content: in the passive condition it stabilizes at $-0.1 \mathrm{~V} \mathrm{SSC}$, in non-passive at about $0.5 \mathrm{~V} \mathrm{SSC}$, and in the active condition at $-1 \mathrm{~V}$ SSC.

Bromides are more prone to cause localised corrosion than other halides. Pitting occurs at significantly lower potential rather than in other electrolytes, suggesting a strong chemical interaction between the passive oxide layer and $\mathrm{Br}^{-}$ions. Localised corrosion was also confirmed by visual inspection after the electrochemical test. Breakdown potential is in the range $2.5 \mathrm{~V}$ and $3 \mathrm{~V}$ SSC. Values are in agreement with interval reported by Casillas et al. [6] and Shizhong [31]. At potential more negative than the redox potential of the $\mathrm{Br} / \mathrm{Br}_{2}$ couple, $+1.2 \mathrm{~V} \mathrm{SSC}$, the passive film is stable,. As the potential is biased to values higher than $1.2 \mathrm{~V} \mathrm{SSC}$, bromide ions are rapidly oxidized at microscopic sites to form bromide gas. This process continues until the conductivity of microscopic sites is reduced, probably for the thickening of the oxide film. Between $2 \mathrm{~V}$ and $3 \mathrm{~V}$ 
SSC, bromide ions are strongly chemisorbed on titanium surface leading to film dissolution and pit growth.

$\mathrm{TiO}_{2}$ behaviour in solution containing iodide ions is intermediate between the one in fluorides (active metal), and chlorides (passive metal without breakdown). The oxide film is uniformly corroded at a slower rate compared to fluorides. No localized corrosion occurred.

Summarizing, results confirm that, although the passive oxide film is responsible of the well-known excellent pitting corrosion resistance, titanium can suffer pitting corrosion in severe working condition. The susceptibility to pitting corrosion is strongly dependent on halides nature [32]. In general, the severity follows the order $\mathrm{Cl}^{-}-\mathrm{I}^{-}-\mathrm{Br}^{-}-\mathrm{F}^{-}$, being fluoride the more aggressive, able to completely dissolve the formed passive layer and bromide able to locally destroy the protective film.

\section{Conclusions}

Titanium anodized at $20 \mathrm{~V}$ in $\mathrm{H}_{2} \mathrm{SO}_{4} 0.5 \mathrm{M}$ was tested in halide salts environment at concentrations of $0.5 \mathrm{M}$ and $2.0 \mathrm{M}$.

At the lower halide concentration, differences between electrolytes are too small to take conclusions; higher concentrations give a better understanding of titanium oxide behaviour in halides.

Anodized titanium is passive in chlorides 2.0 M up to $7 \mathrm{~V} \mathrm{SSC}$, its electrochemical behaviour is the same obtained in neutral, non-aggressive environment containing $\mathrm{Na}_{2} \mathrm{SO}_{4}$. In the presence of bromide ions a typical pitting corrosion occurred with a breakdown potential close to 2.5-3.0 V SSC. Fluorides dissolve titanium oxide film, causing fast uniform corrosion and metal dissolution in soluble salts. Anodized titanium behaviour in iodides is intermediate between chlorides and fluorides, no localized corrosion is observed but a much higher corrosion rate compared to the one obtained in chlorides caused dissolution of the film. 
The susceptibility to pitting corrosion is strongly dependent on halides nature; the severity follows the order $\mathrm{Cl}^{-}-\mathrm{I}^{-}-\mathrm{Br}^{-}-\mathrm{F}^{-}$, being fluoride the more aggressive.

\section{Data Availability}

The raw data and the processed data required to reproduce these findings cannot be shared at this time as the data also forms part of an ongoing study. 


\section{References}

[1] Z. Liu, G.E. Thompson, Formation of porous anodic oxide film on titanium in phosphoric acid electrolyte. J Mater Eng Perform 24 (2015) 59-66

[2] L.L. Shreir, G.T. Burstein, R.A. Jarman, Corrosion. $1^{\text {st }}$ edition, Butterworth-Heinemann, Oxford, Boston, 1994.

[3] D.F. Hasson, C.R. Crowe, Titanium for offshore oil drilling, JOM 34 (1982) 23-28

[4] M. Peters, J. Kumpfert, C.H. Ward, C. Leyens, Titanium alloys for aerospace applications, Titanium and Titanium Alloys, Wiley-VCH Verlag GmbH \& Co. KGaA, 333-350, 2003.

[5] I.V. Gorynin, Titanium alloys for marine application, Mater Sci Eng A 263 (1999) 112-116.

[6] N. Casillas, S. Charlebois, W.H. Smyrl, H.S. White, Pitting corrosion of titanium, J Electrochem Soc, 141 (1994) 636-642.

[7] I. Dugdale, J.B. Cotton, The anodic polarization of titanium in halide solutions. Corros Sci, 4 (1964) 397-411.

[8] D. Prando, A. Brenna, F. Bolzoni, M. Pedeferri, M.V. Diamanti, M. Ormellese, Electrochemical anodizing treatment to enhance localized corrosion resistance of pure titanium, J Appl Biomater Funct Mater 15 (2017) e19-e24.

[9] Z.B.Wang, H.X.Hu, Y.G.Zheng, W.Ke, Y.X. Qiao, Comparison of the corrosion behavior of pure titanium and its alloys in fluoride-containing sulfuric acid, Corros Sci, 103 (2016) 5055

[10] D. Prando, A. Brenna, M.V. Diamanti, S. Beretta, F. Bolzoni, M. Ormellese, M. Pedeferri, Corrosion of titanium: Part 1: aggressive environments and main forms of degradation, $\mathrm{J}$ Appl Biomater Funct Mater 15 (2017) e291 - e302.

[11] H. Kaesche, Die korrosion der metalle, Springer-Verlag, 2011.

[12] F.A. Posey, E.G. Bohlmann, Pitting of titanium alloys in saline waters, Desalination 3 (1967) 269-279. 
[13] T.R. Beck, Pitting of titanium I. Titanium-foil experiments, J Electrochem Soc 120 (1973) 1310-1316.

[14] T.R. Beck, Pitting of titanium II. One-dimensional pit experiments, J Electrochem Soc 120 (1973) 1317-1324.

[15] S. Virtanen, C. Curty, Metastable and stable pitting corrosion of titanium in halide solutions, Corrosion 60 (2004) 643-649.

[16] D. Prando, A. Brenna, M.V. Diamanti, S. Beretta, F. Bolzoni, M. Ormellese, M. Pedeferri, Corrosion of titanium: Part 2: effect of surface treatments, J Appl Biomater Funct Mater (2018) e1 - e11, doi 10.5301/jabfm.5000396.

[17] D. Prando, A. Brenna, M.V. Diamanti, S. Beretta, F. Bolzoni, M. Ormellese, M. Pedeferri, Enhancement of pure titanium localized corrosion resistance by anodic oxidation, Mat and Corr. (2017) 1-7. doi.org/10.1002/maco.201709815.

[18] J.C. Puippe, Surface treatments of titanium implants, Eur Cell Mater 5 (2003) 32-33.

[19] J.H. Liu, G.L. Wu, M. Yu, Influence of incremental rate of anodising current on roughness and electrochemical corrosion of oxide film on titanium alloy Ti-10V-2Fe-3Al, Surf Eng 28 (2012) 406-411.

[20] A. Ketabchi, A. Weck, F. Variola, Influence of oxidative nanopatterning and anodization on the fatigue resistance of commercially pure titanium and Ti-6Al-4V: influence of oxidative nanopatterning and anodization, J Biomed Mater Res B Appl Biomater 103 (2015) 563-571.

[21] J. Liu, L. Wu, M. Yu, Effects of sealing process on corrosion resistance and roughness of anodic films of titanium alloy Ti-10V-2Fe-3Al, J Cent South Univ Technol 18 (2011) 17951801.

[22] T. Aizawa, A. Mitsuo, S. Yamamoto, Self-lubrication mechanism via the in situ formed lubricious oxide tribofilm, Wear, 259 (2005) 708-718.

[23] C. Fu, W. Tian, K. Yang, Effects of sodium tartrate anodizing on fatigue life of TA15 titanium alloy, Chin J Aeronaut 28 (2015) 1281-1286. 
[24] ASTM B861, Standard Specification for Titanium and Titanium Alloy Seamless Pipe, ASTM International, 100 Barr Harbour Dr. P.O. box C-700 West Conshohocken, Pennsylvania, US.

[25] EN ISO 17475, Corrosion of metals and alloys - Electrochemical test methods - Guidelines for conducting potentiostatic and potentiodynamic polarization measurements, European Committee for Standardization, rue de Stassart, 36 B-1050 Brussels

[26] J. Liu, A. Alfantazi, E. Asselin, Effects of temperature and sulfate on the pitting corrosion of titanium in high-temperature chloride solutions, J Electrochem Soc 162 (2015) C189-C196.

[27] G.T. Burstein, C. Liu, R.M. Souto, The effect of temperature on the nucleation of corrosion pits on titanium in Ringer's physiological solution, Biomaterials 26 (2005) 245-256.

[28] D.W. Shoesmith, J.J. Noël, Corrosion of titanium and its alloys, In Stott BCGLLRS edition, Shreirs Corros. Elsevier, Oxford, 2042-2052, 2010.

[29] M. Nakagawa, S. Matsuya, T. Shiraishi, M. Ohta, Effect of fluoride concentration and pH on corrosion behavior of titanium for dental use, J Dent Res 78 (1999) 1568-1572.

[30] B. Lindholm-Sethson, B. Ardlin, Effects of $\mathrm{pH}$ and fluoride concentration on the corrosion of titanium. J Biomed Mater Res A, 86A (2008) 149-159.

[31] H. Shizhong, M. Xiaoxiong, The states of bromide on titanium surface prior to pit initiation, Corros Sci, 31 (1990) 281-286.

[32] J.L. Trompette, L. Massot, L. Arurault, S.Fontorbes, Influence of the anion specificity on the anodic polarization of titanium, Corros Sci, 53 (2011) 1262-1268 